\title{
Metabolic disorders and cardiovascular risk in people living with HIV/AIDS without the use of antiretroviral therapy
}

\author{
Mariana Amaral Raposo[1],[2], Geyza Nogueira de Almeida Armiliato ${ }^{[1],[2],}$ \\ Nathalia Sernizon Guimarães ${ }^{[1],[2]}$, Camila Abrahão Caram ${ }^{[2]}$, \\ Raíssa Domingues de Simoni Silveira ${ }^{[2]}$, and Unaí Tupinambás ${ }^{[2]}$
}

\begin{abstract}
[1]. Programa de Pós-Graduação Stricto Sensu em Ciências da Saúde: Infectologia e Medicina Tropical, Faculdade de Medicina, Universidade Federal de Minas Gerais, Belo Horizonte, MG, Brasil. [2]. Departamento de Infectologia e Medicina Tropical, Faculdade de Medicina, Universidade Federal de Minas Gerais, Belo Horizonte, MG, Brasil.
\end{abstract}

\begin{abstract}
Introduction: Metabolic disorders in people living with HIV/AIDS (PLH) have been described even before the introduction of antiretroviral (ARV) drugs in the treatment of HIV infection and are risk factors for cardiovascular diseases. Based on this, the purpose of this study was to assess metabolic disorders and cardiovascular risk in PLH before the initiation of antiretroviral treatment (ART). Methods: This was a cross-sectional descriptive study of 87 PLH without the use of ART, which was carried out between January and September 2012 at a specialized infectious diseases center in Minas Gerais, Brazil. Results: The main metabolic disorders in the population were low serum levels of HDL-cholesterol, hypertriglyceridemia and abdominal obesity. Dyslipidemia was prevalent in $62.6 \%$ of the study population, whereas metabolic syndrome (MS) was prevalent in $11.5 \%$ of patients assessed by the International Diabetes Federation (IDF) criteria and $10.8 \%$ assessed by the National Cholesterol Education Program-Adult Treatment Panel (NCEP-ATPIII) criteria. Regarding cardiovascular risk, 89.7\% of the population presented a low coronary risk according to the Framingham Risk Score. A greater proportion of patients diagnosed with MS presented low cardiovascular risk ( $80 \%$ assessed by IDF criteria and $77.8 \%$ assessed by NCEP-ATPIII criteria). Conclusions: Metabolic disorders in this population may be due to HIV infection or lifestyle (smoking, sedentary lifestyle and inadequate diet). The introduction of ART can enhance dyslipidemia, increasing cardiovascular risk, especially among those who have classic risks of cardiovascular disease.
\end{abstract}

Keywords: HIV/AIDS. Metabolic disorders. Cardiovascular risk.

\section{INTRODUCTION}

Metabolic disorders in people living with HIV/AIDS (PLH) have been described even before the introduction of antiretroviral (ARV) drugs in the treatment of the infection caused by HIV ${ }^{1}$. Among those for whom antiretroviral therapy (ART) has not been initiated, low-density lipoprotein-cholesterol (LDL-c) and high-density lipoprotein-cholesterol (HDL-c) levels are frequently found, prior to hypertriglyceridemia which is associated with an increase in very low-density lipoproteincholesterol (VLDL-c) levels and normal LDL-c and HDL-c levels ${ }^{2}$.

Lipid and glycemic metabolic disorders, such as dyslipidemia, hypertension, glucose intolerance, insulin resistance, diabetes mellitus (DM) and alterations in body fat distribution can be

Corresponding author: Dr. Unaí Tupinambás.

e-mail: unaitupi@gmail.com

Received 27 June 2017

Accepted 5 October 2017 characterized as metabolic syndromes (MS) ${ }^{1}$. Brazilian studies that assessed the MS prevalence in PLH with and without the use of ART have reported prevalence between $12 \%$ and $38.2 \%$, respectively ${ }^{3-6}$. In PLH with the use of ART, metabolic disorders are more frequent and severe. Dyslipidemia amounts to about $70 \%$ of PLH who use ART and cardiovascular events in these patients are more common than in the general population?

The Strategies for Management of Antiretroviral Therapy (SMART) study was an important clinical study which demonstrated the role of non-infectious complications in PLH, comparing patients in continuous use of ART and PLH on intermittent ART monitored by cluster of differentiation 4 (CD4) cell count, which refer to CD4+ T lymphocytes count, essential cells of the human immune system. This study showed that mortality in the group with use of intermittent ART was higher ${ }^{8}$. The vast majority of the population deaths were related to cardiovascular diseases (CVD). Yet, one of the hypotheses for this outcome was that the events were related to the increase in the inflammation process due to viral replication with subsequent vascular damage ${ }^{9}$. 
The clinical management of PLH has shown some complications related to the increase in survival rate, the aging process of this population, chronic inflammation and its consequences as well as the medium or long-term ART toxicity, besides the classic risk factors of CVD (smoking, sedentary lifestyle, etc. $)^{10}$. Based on this, the aim of this study was to assess the main metabolic disorders and cardiovascular risk in PLH before the initiation of ART.

\section{METHODS}

\section{Study design}

This descriptive cross-sectional study was carried out in a specialized infectious diseases center in Belo Horizonte Minas Gerais, Brazil. The participants of this study comprised 87 PLH without the use of ART, older than 18 years, of both sexes, who have had medical indication for the beginning of ART in the period between January and September 2012 and had biochemical tests results nearing the study inclusion appointment, have been added by convenience.

\section{Ethical considerations}

The Research Ethics Committee of the Federal University of Minas Gerais approved the present study, under protocol number 0251.0.203.000-11, and all participants gave written informed consent.

\section{Data collection}

The data were collected during clinical evaluation (before the initiation of ART) and review of the medical records. During the clinical evaluation, anthropometric data were collected using standardized procedures by the World Health Organization ${ }^{11}$ [weight, height and abdominal circumference (AC)] and filling out questionnaires to evaluate the physical activity level of patients who were categorized in two groups: sedentary individuals and those who undertook at least one physical activity (bodybuilding, aerobics, hiking, running, or pedaling).

The review of medical records was performed after the inclusion consultation and the information registered in specific forms. Demographic data were collected (sex, age and schooling), comorbidity (cardiac disease, DM and hypertension), lifestyle (smoking and alcoholism), and laboratory tests [glycemia, total cholesterol (TC), HDL-c, LDL-c, triglycerides (TG), CD4 count and viral load].

\section{Metabolic profile}

The evaluation of the metabolic profile of the population was conducted by biochemical tests of glucose, TC and fractions (LDL-c and HDL-c), and TG in accordance with the values of the V Brazilian Guidelines on Dyslipidemia and Prevention of Atherosclerosis ${ }^{12}$. The patients were categorized as dyslipidemic when TC $\geq 200 \mathrm{mg} / \mathrm{dl}$, HDL-c $<40 \mathrm{mg} / \mathrm{dl}$ for men and $<50 \mathrm{mg} /$ $\mathrm{dl}$ for women, LDL-c $\geq 160 \mathrm{mg} / \mathrm{dl}$ and $/$ or TG $\geq 150 \mathrm{mg} / \mathrm{dl}^{12}$.

\section{Metabolic syndrome}

The patients were classified according to the criteria of the International Diabetes Federation (IDF) ${ }^{13}$ and the National
Cholesterol Education Program-Adult Treatment Panel (NCEPATPIII) ${ }^{14}$.

The IDF classifies patients with MS according to the presence of abdominal obesity ( $\mathrm{AC}>94 \mathrm{~cm}$ for men and $>80 \mathrm{~cm}$ for women), as a condition sine qua non, and two or more criteria, such as: TG $>150 \mathrm{mg} / \mathrm{dl}$, HDL-c $<40 \mathrm{mg} / \mathrm{dl}$ for men and $<50 \mathrm{mg} / \mathrm{dl}$ for women, systolic arterial pressure $>130 \mathrm{mmHg}$ or treatment for hypertension and diastolic arterial pressure $>85 \mathrm{mmHg}$ or treatment for hypertension.

The NCEP-ATP III, on the other hand, proposes that the individual has MS if there is the presence of at least three of the following criteria: $\mathrm{AC}>102 \mathrm{~cm}$ for men or $>88 \mathrm{~cm}$ for women, HDL-c $<40 \mathrm{mg} / \mathrm{dl}$ for men and $<50 \mathrm{mg} / \mathrm{dl}$ for women, TG $>$ $150 \mathrm{mg} / \mathrm{dl}$, arterial pressure with cut-off values of $130 / 85 \mathrm{mmHg}$ and fasting glucose $>110 \mathrm{mg} / \mathrm{dl}$.

\section{Cardiovascular risk}

A Framingham Risk Score was calculated to evaluate the cardiovascular risk, as proposed by the American Heart Association and the American College of Cardiology according to the results of Framingham Heart Study ${ }^{15}$.

\section{Statistical analyses}

The data collected were recorded in a database, which was built in Excel software (Microsoft Office 2013). Statistical analyses were carried out using the Statistical Package for the Social Sciences (SPSS) software, version 22.0 (SPSS Inc., Chicago, IL, USA).

The data were described as frequencies and percentages for categorical variables, by measures of central tendency (mean or medians) and measures of dispersion [standard deviation (SD) or $25^{\text {th }}-75^{\text {th }}$ percentiles] for numerical variables. To check data normality, the Shapiro-Wilk test was applied.

Continuous variables were compared using the t-test (normal distribution) or the Wilcoxon test (asymmetrical distribution), and frequencies were compared using the chi-square test or Fisher's exact test, where appropriate. For all tests, were considered as level of statistical significance a value of $5 \%$.

\section{RESULTS}

\section{Prevalence of dyslipidemia}

The patients were categorized as dyslipidemic if they presented with abnormalities in biochemical tests, in accordance with the values of the V Brazilian Guidelines on Dyslipidemia and Prevention of Atherosclerosis ${ }^{12}$. The prevalence of dyslipidemia in the study population was $62.6 \%$. The variations in the serum levels of each lipid fraction are shown in Table 1.

\section{Demographic, clinical and laboratorial characteristics}

Seventy-six percent of the patients analyzed (75.9\%) were men. The mean (SD) age of the studied population was 36.57 (9.38) years. There was no significant difference between both sexes and the most frequent level of schooling was high school (49.4\%).

The mean body mass index (BMI) among the male patients was $24.09 \mathrm{~kg} / \mathrm{m}^{2}$ and $23 \mathrm{~kg} / \mathrm{m}^{2}$ for females, with no significant 
TABLE 1

Serum levels of TC, HDL-c, LDL-c and TG in PLH without the use of ART.

\begin{tabular}{lcc}
\hline Baseline (N=87) & Number & Percentage \\
\hline TC $\geq 200 \mathrm{mg} / \mathrm{dl}$ & 14 & 16.1 \\
LDL-c $\geq 160 \mathrm{mg} / \mathrm{dl}$ & 2 & 2.3 \\
HDL-c $<40 \mathrm{mg} / \mathrm{dl}$ for men and $<50 \mathrm{mg} / \mathrm{dl}$ for women & 47 & 54.0 \\
TG $\geq 150 \mathrm{mg} / \mathrm{dl}$ & 25 & 26.4
\end{tabular}

TC: total cholesterol; HDL-c: high-density lipoprotein-cholesterol; LDL-c: low-density lipoprotein-cholesterol; TG: triglycerides; PLH: people living with HIV/AIDS; ART: antiretroviral therapy; HIV/AIDS: human immunodeficiency virus/acquired immunodeficiency syndrome.

\section{TABLE 2}

Demographic and clinical characteristics of PLH without the use of ART according to sex and diagnosis of dyslipidemia

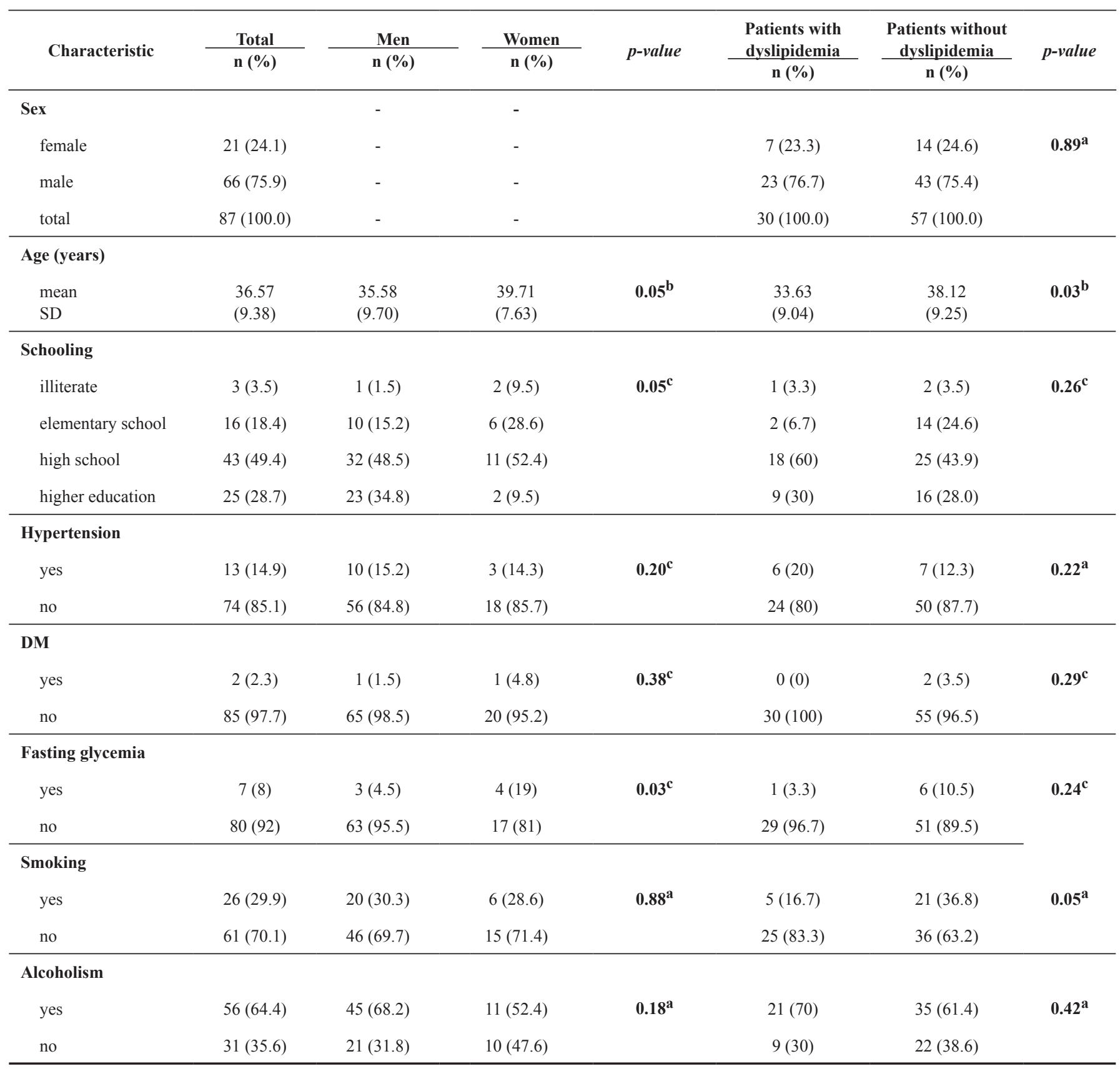

PLH: people living with HIV; ART: antiretroviral therapy; SD: standard deviation; DM: diabetes mellitus; HIV: human immunodeficiency virus. ${ }^{\text {a Chi-square }}$ test. ${ }^{\mathbf{b}}$ Students t-test. ${ }^{\mathbf{c}}$ Fisher's exact test. 
difference; $31 \%$ of the patients of this study presented abdominal obesity according to the NCEP-ATPIII, that classifies the patient with abdominal obesity if there $\mathrm{AC}>94 \mathrm{~cm}$ for men and $>80 \mathrm{~cm}$ for women.

The mean TC level was 168.47 (31.60) mg/dl, HDL-c 40.67 (31.60) $\mathrm{mg} / \mathrm{dl}$, and TG 120.93 (66.60) $\mathrm{mg} / \mathrm{dl}$.

Of the total, $31 \%$ of the patients studied presented CD4 cell counts less than or equal to 200 cells $/ \mathrm{ml}$ and men presented viral load significantly higher than women ( $\mathrm{p}$-value $=0.04$ ). Regarding lifestyle, $29.9 \%$ were smokers, $64.4 \%$ consumed alcoholic beverages, and $58.6 \%$ were sedentary.

Regarding the previous medical history, $3.4 \%$ of the participants had heart disease and $4.6 \%$ had a history of cancer, and $2.3 \%$ of them had Kaposi's sarcoma diagnosed in the same year of human immunodeficiency virus (HIV) diagnosis. The prevalence of hypertension and DM were $14.9 \%$ and $2.3 \%$, respectively.

Table 2 and Table 3 present the demographic, clinical, anthropometric, and laboratorial characteristics according to sex and diagnosis of dyslipidemia.

\section{Prevalence of metabolic syndrome}

According to the criteria defined by the IDF, $11.5 \%$ of the population were classified with MS. In relation to the criteria established by NCEP-ATPIII, this classification occurred in $10.8 \%$ of the population. Each MS component (AC, systolic and diastolic arterial pressure, TG, glucose and HDL-c) was significantly associated with the presence of MS ( $p$-value $<0,05$ ).

Table 4 presents the baseline demographic, clinical and laboratorial characteristics of the participants according to the two definitions of MS (NCEP-ATP III and IDF).

\section{Cardiovascular risk according to Framingham Score}

Regarding the evaluation of the risk of developing cardiovascular events in 10 years, $6.4 \%$ of the population of this study presented intermediate risk and $3.9 \%$ were classified as having high risk. Only increases in age and AC were significantly associated with high risk ( $p$-value $<0.05$ ).

Table 5 presents the demographic, clinical and laboratorial characteristics of the participants according to the Framingham Score.

TABLE 3

Anthropometric and laboratorial characteristics of PLH without the use of ART according to sex and diagnosis of dyslipidemia.

\begin{tabular}{|c|c|c|c|c|c|c|c|}
\hline Characteristic & Total & Men & Women & p-value & $\begin{array}{l}\text { Patients without } \\
\text { dyslipidemia }\end{array}$ & $\begin{array}{l}\text { Patients with } \\
\text { dyslipidemia }\end{array}$ & p-value \\
\hline \multicolumn{8}{|c|}{ Physical activity [n (\%)] } \\
\hline not practice & $51(58.6)$ & $35(53)$ & $16(76.2)$ & $0.06^{\mathrm{a}}$ & $18(60)$ & $33(57.9)$ & $0.85^{\mathrm{a}}$ \\
\hline \multicolumn{8}{|c|}{ BMI per category[n (\%)] } \\
\hline$<18.5$ & $5(5.8)$ & $3(4.5)$ & $2(9.5)$ & \multirow[t]{2}{*}{$0.82^{\mathrm{c}}$} & $0(0)$ & $5(8.8)$ & \multirow[t]{2}{*}{$0.02^{\mathrm{c}}$} \\
\hline $18.5-24.9$ & $51(58.6)$ & $40(60.6)$ & $11(53.4)$ & & $23(76.7)$ & $28(49.1)$ & \\
\hline \multicolumn{8}{|c|}{ CD4-cell count (cells/mm ${ }^{3}$ ) } \\
\hline $\begin{array}{l}\text { Mean } \\
\text { SD }\end{array}$ & $\begin{array}{c}264.93 \\
(152.12)\end{array}$ & $\begin{array}{c}263.60 \\
(151.39)\end{array}$ & $\begin{array}{c}269.09 \\
(158.09)\end{array}$ & $0.65^{b}$ & $\begin{array}{c}309.90 \\
(142.25)\end{array}$ & $\begin{array}{c}241.26 \\
(152.99)\end{array}$ & $0.04^{b}$ \\
\hline \multicolumn{8}{|c|}{ CD4-cell count per category [n (\%)] } \\
\hline$\leq 200$ cells $/ \mathrm{ml}$ & $27(31)$ & $22(33.3)$ & $5(23.8)$ & \multirow[t]{3}{*}{$0.54^{\mathrm{c}}$} & $6(20)$ & $21(36.8)$ & \multirow[t]{3}{*}{$0.27^{\mathrm{c}}$} \\
\hline $201-499 \mathrm{cells} / \mathrm{ml}$ & $55(63.2)$ & $41(62.1)$ & $14(66.7)$ & & $22(73.3)$ & $33(57.9)$ & \\
\hline$\geq 500$ cells $/ \mathrm{ml}$ & $5(5.8)$ & $3(4.6)$ & $2(9.5)$ & & $2(6.7)$ & $3(5.3)$ & \\
\hline \multicolumn{8}{|c|}{ Last viral load (copies/ml) median } \\
\hline
\end{tabular}

PLH: people living with HIV; ART: antiretroviral therapy; BMI: body mass index; SD: standard deviation; DM: diabetes mellitus; HIV: human immunodeficiency virus. ${ }^{\text {a }}$ Chi-square test. ${ }^{\mathbf{b}}$ Wilcoxon test. ${ }^{\mathbf{c}}$ Fisher's exact test. 


\section{TABLE 4}

Demographic, clinical and laboratorial characteristics of PLH without the use of ART with regard to MS.

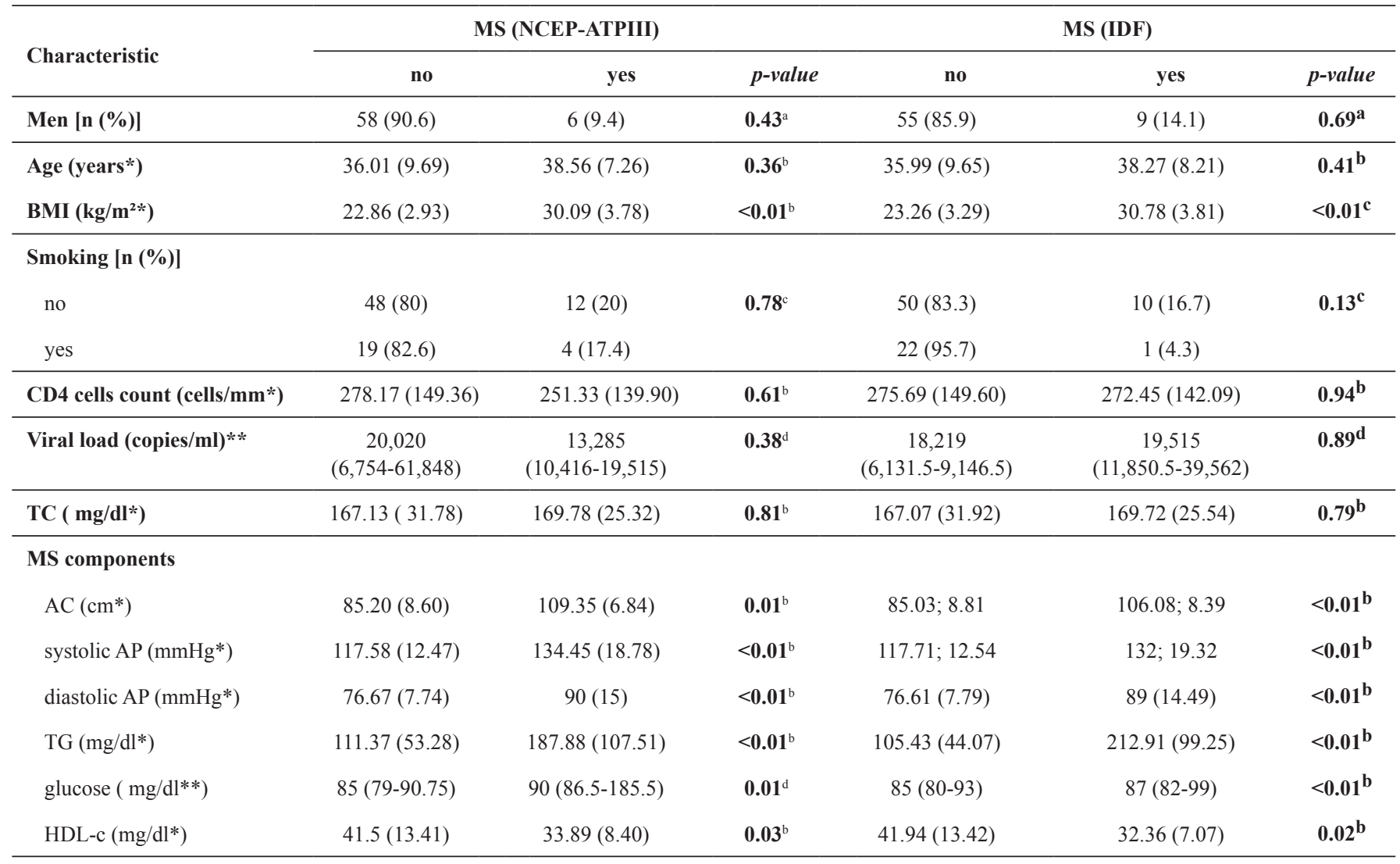

PLH: people living with HIV; ART: antiretroviral therapy; MS: metabolic syndrome; NCEP-ATP-III: National Cholesterol Education Program-Adult Treatment Panel III; IDF: International Diabetes Federation; BMI: body mass index; CD4: cluster of differentiation; TC: total cholesterol; AC: abdominal circumference; AP: arterial pressure; TG: triglycerides; HDL-c: HDL-cholesterol; HIV: human immunodeficiency virus; SD: standard deviation. ${ }^{\mathbf{a}} \mathrm{Chi}-\mathrm{square}$ test. ${ }^{\mathbf{b}}$ Student t-test. ${ }^{\mathbf{c}}$ Fisher's exact test. ${ }^{\mathbf{d}}$ Wilcoxon test. $*$ Rate $(\mathrm{SD}) .{ }^{* *}$ median $\left(25^{\text {th }}-75^{\text {th }}\right.$ percentiles $)$.

\section{DISCUSSION}

The IDF and NCEP-ATPIII are the main criteria utilized for the diagnosis of MS because of their simple clinical and epidemiologic application ${ }^{16}$. The prevalence of MS identified in this study agreed with Wand et al. ${ }^{17}$ who evaluated the prevalence of MS $(8.5 \%$ and $7.8 \%$ by the IDF and NCEPATPIII criteria, respectively) in PLH without the use of ART, but did not agree with the prevalence of Nguyen et al. ${ }^{18}$, who reported the prevalence of MS $(26.5 \%$ and $24.1 \%$ by the IDF and NCEP-ATPIII criteria, respectively) in PLH $93 \%$ of whom were on ART.

The prevalent components of MS in this study were low HDL-c $(54 \%)$, abdominal obesity $(31 \%)$ and hypertriglyceridemia (26.4\%). Similar results were obtained in other studies conducted among PLH, such as the study by Vidigal et al. ${ }^{19}$, who demonstrated a higher prevalence of low HDL-c and hypertriglyceridemia between MS components.

In the dyslipidemic group, the CD4 cell count was significantly lower than that in patients without dyslipidemia, which is not in accordance with the study by Farhi et al. ${ }^{20}$. CD4 cell count is a strong predictor of opportunistic infections, as well as non-infectious diseases ${ }^{8}$.
Garcez et al. ${ }^{21}$ found a prevalence of $59.74 \%$ of dyslipidemia in a population-based study in São Paulo - Brazil. Farhi et al..$^{20}$ observed a prevalence of $77.5 \%$ in dyslipidemia among PLH; such prevalence has been associated mainly with the use of ART, more specifically patients taking protease inhibitors. These patients without the use of ART, explained the Farhi ${ }^{20}$ et al.'s finding, as the introduction of ART is associated with the development of metabolic disorders.

According to Lazzaretti et al. $^{22}$, the risk of development of dyslipidemia in PLH with the use of ART in Brazil may be $70 \%$. A Brazilian study evaluated PLH with and without the use of ART and observed significantly higher values of TC, LDL-c and TG in the population with the use of ART, illustrating the importance of identification of metabolic disorders before the initiation of ART, and adopting a multidisciplinary approach in this population with the aim of lifestyle modification ${ }^{23}$.

The mean age of this population is representative of the prevalence of HIV/AIDS cases notified in $\mathrm{Brazil}^{24}$, and lower compared to other studies that assessed the frequency of metabolic disorders in PLH ${ }^{10,20}$. The patients with dyslipidemia were significantly older than those without this comorbidity. HIV infection is a chronic condition and the aging of this 
TABLE 5

Demographic, clinical and laboratorial characteristics of PLH without the use of ART with regard to Framingham Risk Score.

\begin{tabular}{|c|c|c|c|}
\hline Characteristic & \multicolumn{3}{|c|}{ Cardiovascular risk according to Framingham risk score } \\
\hline MS/IDF [n (\%)] & $8(80)$ & $2(20)$ & $0.22^{\mathrm{b}}$ \\
\hline Age (years)* & $34.87(8.15)$ & $51.25(8.05)$ & $<0.01^{\mathrm{b}}$ \\
\hline \multicolumn{4}{|l|}{ Smoking [n (\%)] } \\
\hline no & $52(94.5)$ & $3(5.5)$ & $0.02^{\mathrm{a}}$ \\
\hline yes & $17(77.3)$ & $5(21.7)$ & \\
\hline CD4-cell count $\left(\text { cells } / \mathrm{mm}^{3}\right)^{*}$ & $277.42(150.19)$ & $175.77(164.02)$ & $0.06^{\mathrm{b}}$ \\
\hline $\mathrm{TC}(\mathrm{mg} / \mathrm{dl})^{*}$ & $168.52(30.88)$ & $172.50(46.65)$ & $0.74^{\mathrm{b}}$ \\
\hline \multicolumn{4}{|l|}{ MS components } \\
\hline $\mathrm{AC}(\mathrm{cm})^{*}$ & $86.99(11.25)$ & $96.20(13.63)$ & $0.04^{\mathrm{b}}$ \\
\hline systolic AP (mmHg)* & $118.11(12.83)$ & $135.71(22.25)$ & $0.08^{\mathrm{b}}$ \\
\hline diastolic AP (mmHg)* & $77.27(9.53)$ & $84.29(12.72)$ & $0.20^{\mathrm{b}}$ \\
\hline TG (mg/dl)* & $115.42(53.66)$ & $164.37(108.90)$ & $0.24^{\mathrm{b}}$ \\
\hline glucose $(\mathrm{mg} / \mathrm{dl})^{* *}$ & $85(79-90)$ & $86.5(83.5-88.5)$ & $0.52^{\mathrm{c}}$ \\
\hline
\end{tabular}

PLH: people living with HIV; ART: antiretroviral therapy; MS: metabolic syndrome; NCEP-ATP-III: National Cholesterol Education Program-Adult Treatment Panel III; IDF: International Diabetes Federation; BMI: body mass index; CD4: cluster of differentiation; TC: total cholesterol; AC: abdominal circumference; AP: arterial pressure; TG: triglycerides; HDL-c: HDL-cholesterol; HIV/AIDS: human immunodeficiency virus/acquired immunodeficiency syndrome; SD: standard deviation. ${ }^{\mathbf{a}}$ Fisher's exact test. ${ }^{\mathbf{b}}$ Student t-test. ${ }^{\mathbf{c}}$ Wilcoxon test. ${ }^{*}$ Rate (SD). ${ }^{* *}$ median $\left(25^{\text {th }}-75^{\text {th }}\right.$ percentiles $)$.

population increases the risk of non-infectious diseases and can affect the quality of life ${ }^{20}$.

The population of this study, in general, demonstrated a low risk to the development of cardiovascular events, which can be explained by the mean age. The increase in age correlated with an increase in cardiovascular risk. The patients with intermediary and high risk were significantly older than patients with low risk. Other studies have also found out a correlation in their analyses, pointing out that the cardiovascular risk in patients infected by HIV after they are 45 seem to have increased whenever compared to populations without this infection ${ }^{25}$.

The increase in cardiovascular risk among PLH is due to a number of factors, including lipid disorders. The first few years of using ARV constitute the period of greatest vulnerability. The rapid recuperation of the immune system during this period may be responsible for atherogenic alterations in the arterial walls ${ }^{26}$.

The results of this study are in accordance with the Data collection on Adverse events of Anti-HIV Drugs (DAD) study ${ }^{27}$, in terms of the median age (37.1 in DAD vs.
36.6 years), proportion of men ( $75.9 \%$ vs. $75.9 \%)$, presence of $\operatorname{DM}(2.8 \% v s .2 .3 \%)$, and mean BMI (23vs. $\left.23.9 \mathrm{~kg} / \mathrm{m}^{2}\right)$. In the base population, the prevalence of dyslipidemia in the DAD study was $45.9 \%$, which was lower $(62.6 \%)$ than that of this study. In addition, there were higher proportions of smokers $(56.2 \%)$ and hypertensive patients (14.9\%) compared to this study (29.9\% and $7.2 \%$, respectively). This difference could be due to the difference in localities in which the studies were conducted (the DAD study was carried in 21 clinics in Europe, United States of America and Australia). In addition, the disparity in the prevalence of dyslipidemia can be explained, partly, by culture, eating habits and differences in physical activity level.

A Brazilian study has shown that obesity is the most important nutritional abnormality among $\mathrm{PLH}^{28}$. All the participants of this study who were considered obese by the classification of BMI had some sort of dyslipidemia. The excess of corporal fat is a predisposing factor for hypertension and a risk factor for the development of other chronic degenerative diseases, such as CVD. When BMI reaches levels higher than $25 \mathrm{~kg} / \mathrm{m}^{2}$, the risk of DM can also increase progressively ${ }^{29}$. 
The participants of the study who were diagnosed with MS had higher BMI compared to other participants without this diagnosis, in agreement with the results of Wand et al. ${ }^{17}$. Excess weight was correlated with increased AC, exhibiting increased visceral fat. Android-type obesity, defined as the accumulation of visceral fat with predominant central or abdominal distribution, has a strong correlation with metabolic disorders and consequently better discriminatory cardiovascular risk results when compared to $\mathrm{BMI}^{30}$. Beraldo et al. ${ }^{31}$ demonstrated that $\mathrm{AC}$ attained the best performance in comparing the anthropometric indicators for the identification of MS among PLH.

The prevalence of fasting glycemia in this study has been greater in women than men. In 2013, the prevalence of DM in the Brazilian population older than 18 years was $6.2 \%$, and was higher in women ${ }^{32}$. The number of diabetic patients has increased due to the growth and aging of the population, the acceleration of urbanization, the progressive prevalence of obesity and sedentary lifestyle, as well as the improved survival of patients with $\mathrm{DM}^{33}$. The introduction of ART can even improve the occurrence of glycemic alterations, suggesting a relation between HIV infection and increased glycemia, probably through the virus acting in the function of $\beta$ pancreatic cells, as well as in the mechanisms of secretion and action of insulin ${ }^{33}$. Studies evaluating insulin resistance in PLH showed that this connection may be aggravated in patients on ART, especially those in the IP class, which may occur by inhibiting the activity of GLUT1 and GLUT4 glucose transporters in the plasma membrane, inhibiting the differentiation of preadipocytes into adipocytes and the induction of mature adipocyte apoptosis ${ }^{34,35}$.

Among the scores that assess the risk for CVD, the most popularized was originated in the Framingham Heart Study ${ }^{15}$. However, the Framingham Risk Score has limitations for analysis in HIV-positive populations since it does not consider in its calculation the inflammatory process that occurs throughout the course of HIV infection. In addition, a third of the population in this study had CD4 cell counts below 200 cells $/ \mathrm{ml}$, indicating late diagnoses of infection. When the CD4 cell count is less than 350 cells $/ \mathrm{ml}$, the risk of severe complications increases considerably $^{36}$.

For the evaluation of cardiovascular risk, some studies have focused on the research of subclinical data, such as thickening of the intimal layers of the coronary arteries and aorta. In the studies analyzed by Currier et al..$^{37}$, the mean cardiovascular risk of PLH from the United States, Canada and Europe was 1.5 times higher than that of uninfected patients. Significant thickening of the coronary intimal layer and the presence of atherosclerotic plaques was prevalent in $50 \%$ of the HIVpositive population, compared to $23 \%$ of the uninfected population. Thus, the analysis of subclinical data points to a higher cardiovascular risk in PLH showing, together with the data mentioned above, that the Framingham Risk Score could have been underestimated in these patients ${ }^{37}$.

A model of cardiac risk assessment created in a study for longitudinal assessment of cardiac risk in PLH performed better than the Framingham Risk Score but did not have its validity extended to other out-of-study populations ${ }^{38}$. Although the Framingham Risk Score is not the ideal tool for assessing cardiovascular risk in PLH, it is still the most widely used tool in studies evaluating cardiovascular risk ${ }^{39}$.

There was a greater prevalence of patients diagnosed with MS who presented low cardiovascular risk $(80 \%$ assessed by the IDF criteria and $77.8 \%$ by the NCEP-ATPIII criteria), but these patients were significantly younger. Among patients with MS who have low cardiovascular risk, the introduction of ART may worsen dyslipidemia, conferring an increase in cardiovascular risk, since lipid risk factors preceded the initiation of treatment with these drugs.

This study presents limitations mainly regarding the nonexclusion of patients who reported to have used drugs to control dyslipidemia (5\%) and other medications that could interfere with the analysis of metabolic disorders. This study used an HIV-positive cohort without the use of ART representative of the population of a specialized infectious diseases center in Southeastern Brazil, so the results of this study may not be generalizable to other PLHs without the use of ART that receive care outside this health system. In addition, the population was predominantly male $(75.9 \%)$ and statistical difference was observed between the sexes only related to viral load, which was higher among males (21,282 copies/mL vs. 12,449 copies/ $\mathrm{mL}$; -value $=0.04$ ).

Future studies will explore the impact of metabolic disorders on the initiation of ART and its role as a cardiovascular risk factor, aiming at a better understanding of how these drugs affect patients' lipid metabolism and their impact on the evolution and prognosis of HIV infection.

In our study, it was possible to identify metabolic disorders in the population evidenced mainly by low serum levels of HDL-c, increased triglycerides and abdominal obesity. Disorders in the metabolic profile in this population may be due to HIV infection or lifestyles such as smoking, sedentary lifestyle and inadequate diets, which may be aggravated by exposure to ART.

Based on the data presented, it is concluded that the majority of patients have a low risk of coronary event in 10 years, however, with a high prevalence of dyslipidemia before the initiation of ART. Lipid and glycemic control and the stratification of cardiovascular risk are mandatory in the follow up of these patients, especially amongst patients with MS who have low cardiovascular risk, since the introduction of ART may potentiate dyslipidemia, conferring an increase in the cardiovascular risk.

\section{Financial support}

Cooperação Técnica Departamento Nacional DST AIDS e HIV- Escritório das Nações Unidas sobre Drogas e Crime. Projeto BRA/K57 (Edital 01/2013 Cooperação Técnica).

\section{Conflict of interest}

The authors declare there is no conflict of interest. 


\section{REFERENCES}

1. Kibirige D, Ssekitoleko R. Endocrine and metabolic abnormalities among HIV-infected patients: a current review. Int J STD AIDS. 2013;24(8):603-11.

2. Stein JH. Dyslipidemia in the era of HIV protease inhibitors. Prog Cardiovasc Dis. 2003;45(4):293-304.

3. Lauda LG, Mariath AB, Grillo LP. Metabolic syndrome and its components in HIV-infected individuals. Rev Assoc Med Bras. 2011;57(2):182-6.

4. Diehl LA, Dias JR, Paes ACS, Thomazini MC, Garcia LR, Cinagawa E, et al. Prevalence of HIV-associated lipodystrophy in Brazilian outpatients: relation with metabolic syndrome and cardiovascular risk factors. Arq Bras Endocrinol Metab. 2008;52(4):658-67.

5. Silva E, Bassichetto KC, Lewi DS. Lipid profile, cardiovascular risk factors and metabolic syndrome in a group of AIDS patients. Arq Bras Cardiol. 2009;93(2):107-11.

6. Troian MC, Castilhos C, Castilhos M, Bialeski N. Metabolic syndrome and dislipidemia prevalence in HIV-positive patients in antiretroviral therapy use. J Bras Med. 2005;89(3):31-4.

7. Montessori V, Press N, Harris M, Akagi L, Montaner JSG. Adverse effects of antiretroviral therapy for HIV infection. CMAJ. 2004;170(2):229-38.

8. El-Sadir W, Lundgren J, Neaton JD, Gordin F, Abrams D, Arduino RC, et al. The Strategies for Management of Antiretroviral Therapy (SMART) Study Group. N Engl J Med. 2006;355(22):2283-96.

9. Phillips AN, Carr A, Neuhaus J, Visnegarwala F, Prineas R, Burman WJ, et al. Interruption of antiretroviral therapy and risk of cardiovascular disease in persons with HIV-1 infection: exploratory analyses from the SMART trial. Antivir Ther. 2008;13(2):177-87.

10. Silva IRP, Dias RM, Mendes ANL, Libonati RMF, Dutra CDT. Dyslipidemia and nutritional status in patients HIV positive with syndrome lipodystrophy. Rev Epidemiol Control Infect. 2014;4(3)200-7.

11. World Health Organization (WHO). Physical status: the use and interpretation of anthropometry. Report of a WHO Expert Committee. Geneva: WHO. Technical Report Series No 854; 1995.

12. Sposito AC, Caramelli B, Fonseca FA, Bertolami MC, Afiune Neto A, Souza AD, et al. Sociedade Brasileira de Cardiologia. IV Brazilian Guideline for dyslipidemia and atherosclerosis prevention: Department of Atherosclerosis of Brazilian Society of Cardiology. Arq Bras Cardiol. 2007;88(Suppl 1):2-19.

13. Alberti KGMM, Zimmet P, Shaw J. The IDF consensus worldwide definition of the metabolic syndrome. Lancet. 2005;366:1059-62.

14. National Cholesterol Education Program (NCEP). Cleeman JI. Expert Panel on Detection, Evaluation and Treatment of High Blood Cholesterol in Adults. Executive summary of the third report of the National Cholesterol Education Program (NCEP) expert panel on detection, evaluation, and treatment of high blood cholesterol in adults (adult treatment panel III). JAMA 2001;285(19):2486-97.

15. Pearson TA, Blair SN, Daniels SR, Eckel RH, Fair JM, Fortmann SP, et al. AHA guidelines for primary prevention of cardiovascular disease and stroke: 2002 update. Circulation. 2002;106(3):388-91.

16. Huang PLA. Comprehensive definition for metabolic syndrome. Dis Model Mech. 2009;2(5-6):231-7.

17. Wand H, Calmy A, Carey DL, Samaras K, Carr A, Law MG, et al. Metabolic syndrome, cardiovascular disease and type 2 diabetes mellitus after initiation of antiretroviral therapy in HIV infection. Aids. 2007;21(18):2445-53.

18. Nguyen KA, Peer N, de Villiers A, Mukasa B, Matsha TE, Mills EJ, et al. Metabolic syndrome in people living with human immunodeficiency virus: an assessment of the prevalence and the agreement between diagnostic criteria. Int $\mathrm{J}$ Endocrinol. 2017;2017:1613657.

19. de Carvalho Vidigal F, Bressan J, Babio N, Salas-Salvadó J. Prevalence of metabolic syndrome in Brazilian adults: a systematic review. BMC Public Health. 2013;13:1198.

20. Farhi L, Lima DB, Cunha CB. Dyslipidemia in HIV/AIDS patients in antiretroviral therapy in a university hospital, Rio de Janeiro, Brazil. J Bras Patol Med Lab. 2008;44(3):175-84.

21. Garcez MR, Pereira JL, Fontanelli MM, Marchioni MML, Fisberg RM. Prevalence of dyslipidemia according to the nutritional status in a representative sample of São Paulo. Arq Bras Cardiol. 2014;103(6):476-84.

22. Lazzaretti RK, Kuhmmer R, Sprinz E, Polanczyk CA, Ribeiro JP. Dietary intervention prevents dyslipidemia associated with highly active antiretroviral therapy in human immunodeficiency virus type 1-infected individuals: a randomized trial. J Am Coll Cardiol. 2012;59(11):979-88.

23. Abreu LM, Escosteguy CC, Sodré CN, Godomiczer A, Passoni LF, Menezes J. Antiretroviral treatment and hypercholesterolemy in the HIV-positive population. Rev SOCERJ. 2006;19(3):219-24.

24. Ministério da Saúde (MS). Boletim epidemiológico AIDS e DST. Bol Epidemiol AIDS. 2015;6(1).

25. Currier J, Bartlett JG, Bloom A. Epidemiology of cardiovascular disease and risk factors in HIV-infected patients. UpToDate [internet]; 2016. [updated 2016 June 18; cited 2017 Apr 5]. Available from: http://www.uptodate.com/contents/epidemiology-ofcardiovascular-disease-and-risk-factors-in-hiv-infected-patients

26. Kramer AS, Lazzarotto AR, Spinz E, Manfroi WC. Metabolic abnormalities, antiretroviral therapy and cardiovascular disease in elderly patients with HIV. Arq Bras Cardiol. 2009;93(5):561-8.

27. Friss-Meller N, Sabin CA, Weber R, Monforte AD, El-Sadr WM, Reiss P, et al. Data collection on adverse events of anti-hiv drugs (dad) study group. Combination antiretroviral therapy and the risk of myocardial infarction. N Engl J Med. 2004;350(9):955.

28. Jaime PC, Florinfo AA, Latorrre MRDO, Brasil BG, Santos ECM, Segurado AAC. Prevalence of overweight and central obesity in HIV/AIDS patients treated with highly active antiretroviral therapy. Rev Bras Epidemiol. 2004;7(1):65-72.

29. Oliveira AFCD, Nogueira MS. Obesity as risk factor associated with hypertension among nursing professionals of a national philanthropy health institution. Rev Esc Enferm USP. 2010;44(2):388-94.

30. Ho SY, Lam TH, Janus ED. Waist to stature ratio is more strongly associated with cardiovascular risk factors than other simple anthropometric indices. Ann epidemiol. 2003;13(10):683-91.

31. Beraldo RA, Meliscki GC, Silva BR, Navarro AM, Bollela VR, Schmidt A, et al. Comparing the ability of anthropometric indicators in identifying metabolic syndrome in HIV patients. PloS One. 2014;11(2):e0149905.

32. Instituto Brasileiro de Geografia e Estatística (IBGE). Pesquisa Nacional de Saúde 2013: percepção do estado de saúde, estilos de vida e doenças crônicas - Brasil, Grandes Regiões e Unidades da Federação [Internet]. Rio de Janeiro: IBGE; 2014. [atualizado 2016 junho 9; citado 2017 apr 4]. Disponível em: ftp://ftp.ibge.gov.br/ PNS/2013/pns2013.pdf.

33. Milech A, Angelucci AP, Golbert A, Carrilho AJF, Ramalho AC, Aguiar ACB. Brazilian Society Guideline of Diabetes (2015-2016). São Paulo: AC Farmacêutica; 2016.

34. Dubé MP. Disorders of glucose metabolism in patients infected with human immunodeficiency virus. Clin Infect Dis. 2000;31(6):1467-75. 
35. Ben-Romano R, Rudich A, Torok D, Vanounou S, Riesenberg K, Schlaeffer F, et al. Agent and cell-type specificity in the induction of insulin resistance by HIV protease inhibitors. Aids. 2003;17(1): $23-32$.

36. Ministério da Saúde (MS). Protocolo clínico e diretrizes terapêuticas para manejo da infecção pelo HIV em adultos. Aids. 2013;1-75.

37. Currier J, Bartlett J, Bloom A. Pathogenesis and biomarkers of cardiovascular disease in HIV-infected patients. UpToDate [internet]; 2016. [Updated 2016 June 18; cited 2017 Apr 5]. Available from: http://www.uptodate.com/contents/pathogenesis-and-biomarkers-ofcardiovascular-disease-in-hiv-infected-patients

38. Friis-Møller N, Thiebaut R, Reiss P, Weber R, Monforte ADA, De Wit $\mathrm{S}$, et al. Predicting the risk of cardiovascular disease in HIVinfected patients: the data collection on adverse effects of anti-HIV drugs study. Eur J Cardiovasc Prev \& Rehabil. 2010;17(5):491-501.

39. Brock PW, Valério CC, Bohnke PL, Carmes E, Sobrinho MIAH. Metabolic profile of HIV-infected patients - Hospital de Clínicas de Curitiba. Rev Med UFPR. 2015.2(3):102-8.

\section{Erratum}

\section{Revista da Sociedade Brasileira de Medicina Tropical/Journal of the Brazilian Society of Tropical Medicine Vol.50(5): Table 2 - page 600, September-October, 2017 - doi: 10.1590/0037-8682-0258-2017}

TABLE 2

Demographic and clinical characteristics of PLH without the use of ART according to sex and diagnosis of dyslipidemia

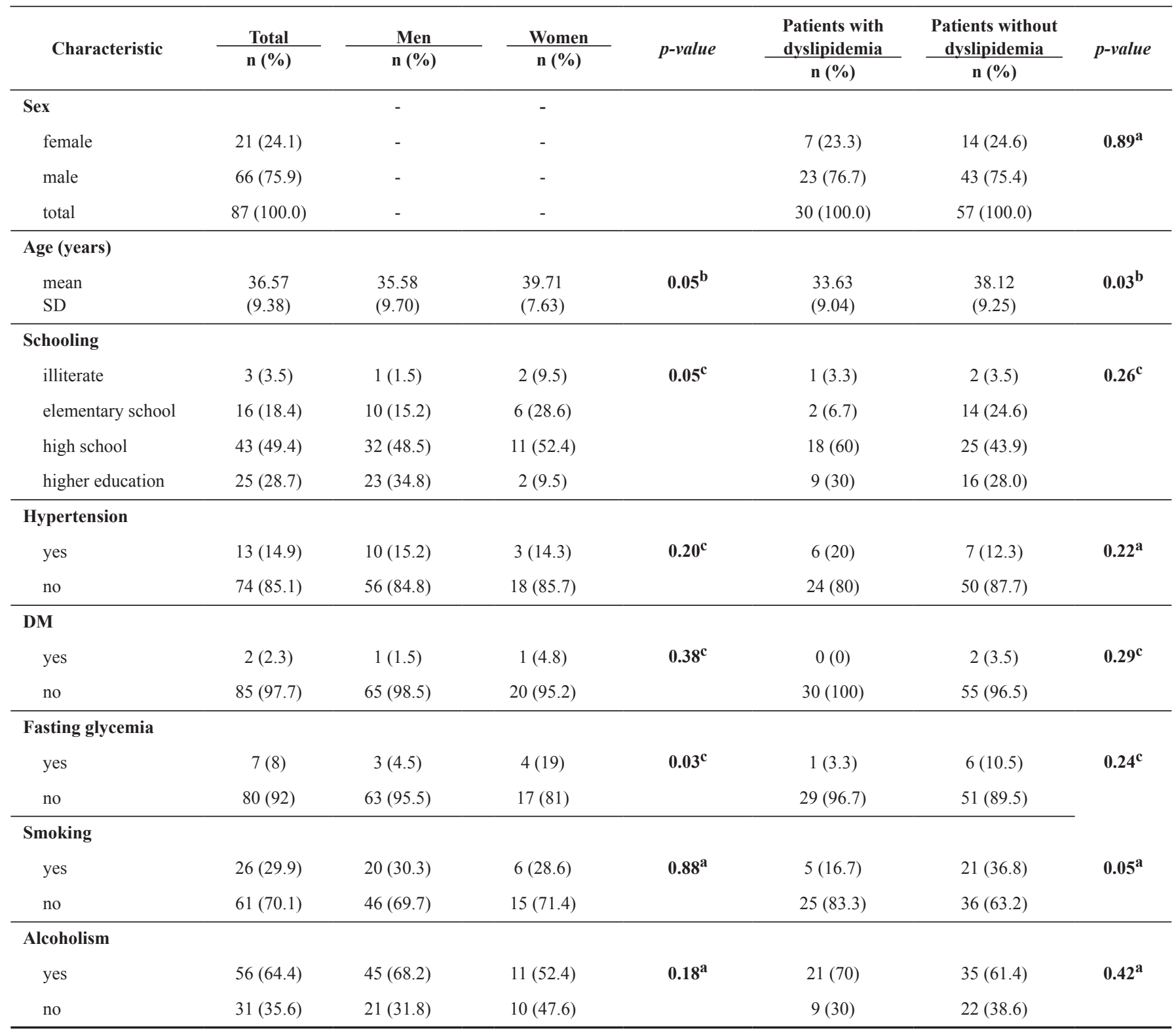

PLH: people living with HIV; ART: antiretroviral therapy; SD: standard deviation; DM: diabetes mellitus; HIV: human immunodeficiency virus. ${ }^{\text {a Chi-square }}$ test. '' Students t-test. ${ }^{\mathbf{c}}$ Fisher's exact test. 
Should read:

TABLE 2

Demographic and clinical characteristics of PLH without the use of ART according to sex and diagnosis of dyslipidemia

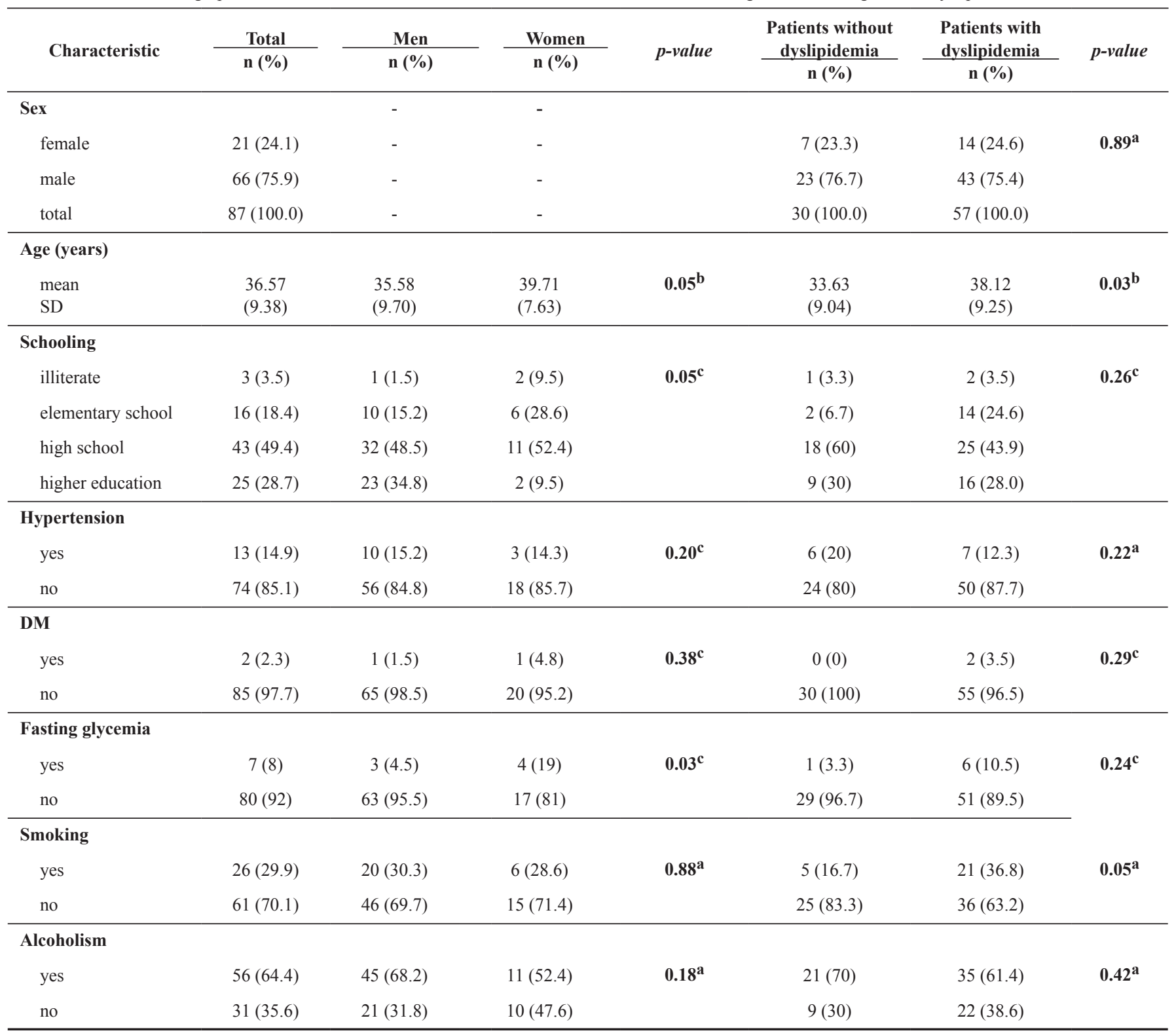

PLH: people living with HIV; ART: antiretroviral therapy; SD: standard deviation; DM: diabetes mellitus; HIV: human immunodeficiency virus. ${ }^{\text {a } C h i-s q u a r e ~}$ test. ${ }^{\mathbf{b}}$ Students t-test. ${ }^{\mathbf{c}}$ Fisher's exact test. 